\title{
The Development of a
Rasch-Type Loneliness Scale
}

\author{
Jenny de Jong-Gierveld and Fans Kamphuis \\ Pree University Amstordam
}

This paper describes an attempt to construct a measuring instrument for loneliness that meets the criteria of a Rasch scale. Rasch $(1960,1966)$ proposed a latent trait model for the unidimensional scaling of dichotomous items that does not suffer from the inadequacies of classical approaches. The resulting Rasch scale of this study, which is based on data from 1,201 employed, disabled, and jobless adults, consists of five positive and six negative items. The positive items assess feelings of belongingness, whereas the negative items apply to three separate aspects of missing relationships. The techniques for testing the assumptions underlying the Rasch model are compared with their counterparts from classical test theory, and the implications for the methodology of scale construction are discussed.

An increasing number of studies on loneliness have become possible through the development of a number of thoroughly validated loneliness measuring instruments. Studies concerning loneliness have been carried out in the United States and in Canada, as well as in the Netherlands. An overview of this research can be found in Peplau and Perlman (1982), and in Hartog, Audy, and Cohen (1980). An extensively used measuring instrument is the UCLA Loneliness Scale (Russell, Peplau, \& Cutrona, 1980; Russell, Peplau, \& Ferguson, 1978), which is a unidimensional scale, developed and tested on a college student population. De Jong-

APPLIED PSYCHOLOGICAL MEASUREMENT

Vol. 9, No. 3, September 1985, pp. 289-299

(1) Copyright 1985 Applied Psychological Measurement Inc. 0146-6216/85/030289-11\$1.80
Gierveld has developed a scale that is based on a multidimensional conceptualization of loneliness, and it has been validated in several surveys among married, unmarried, divorced, and widowed men and women (de Jong-Gierveld, 1978; de Jong-Gierveld \& Raadschelders, 1982). (For a further discussion of these loneliness scales, see Russell, 1982.)

The present paper first outlines the conceptualization of loneliness and describes the resulting loneliness measuring instrument. Subsequently, an overview is presented of the work done in developing an improved loneliness scale that meets the criteria of the Rasch model ( $\mathbb{R a s c h}, 1960,1966$ ). A final section examines the resulting Rasch-based loneliness scale and a number of loneliness subscales.

\section{The Mratidionensional Constrenct of Lonelingess}

Loneliness was found to pertain to the manner in which persons perceive, experience, and evaluate their isolation and lack of communication with others. Loneliness involves situations in which the number of achieved relationships is smaller than desired, or when the existing relationships fail to attain the desired degree of intimacy. It is important to distinguish these subjective feelings of toneliness from objective social isolation. Objective social isolation refers to the lack of lasting interpersonal relationships. The original notions concerning the 
complex nature of loneliness were influenced by the ideas of Weiss (1973) and a content analysis of the life histories of 114 lonely men and women (de Jong-Gierveld, 1984). On the basis of these and further pilot data, three dimensions of loneliness were distinguished:

1. Type of deprivation. This dimension refers to the nature and intensity of the missing relationships. To determine the type of deprivation, knowledge is required about the relationships that a person considers essential, something which will vary according to the category of individuals under investigation (Gordon, 1976; Weiss, 1973).

2. Time perspective. This dimension differentiates between people who experience loneliness as being unchangeable and people who experience loneliness as temporary.

3. Emotional characteristics. These refer to the absence of positive feelings such as happiness and affection, and to the presence of negative feelings such as fear, sadness, and uncertainty. The first component, the presence of a certain intensity of deprivation, was considered to be the essence of loneliness.

\section{The Development of a Lomeliness Scale}

A 34-item set was developed, incorporating the three dimensions of loneliness. These items were utilized in a survey conducted among 556 single, married, divorced, and widowed adult men and women, whose names and addresses were selected at random from the population registers of three cities. Initial analysis, using the MINISSA nonmetric scaling techniques (Roskam, 1977) and the JOHNSON procedure of nonmetric hierarchical cluster analysis (Anderberg, 1973; Johnson, 1967; Overall $\&$ Klett, 1972), indicated that 32 of the 34 items clustered in the three dimensions, as expected. Nine of the items constituted the deprivation scale assessing the intensity of deprivation feelings concerning relationships with others. (Cronbach's $\alpha$ $=.86$; item-rest correlations were all over .50.) These items are presented, among others, in Table 1 .
A deprivation score was computed, based on the simple sum of the number of items with which the respondent agreed. The correlation between the score on the deprivation scale and the score on a selfrating loneliness scale (de Jong-Gierveld, 1984) was highly significant: $r=.66, p<.001$. Individuals who obtained high scores on the deprivation scale were more likely to rate themselves as lonely than were other respondents.

Because the deprivation scale was primarily found to measure severe feelings of loneliness, improvement seemed desirable. It was considered necessary to develop a loneliness scale that would (1) assess severe feelings of loneliness as well as less intense loneliness feelings, (2) consist of negatively as well as positively formulated items, and (3) represent a latent continuum of deprivation. In addition, the new loneliness scale should conform to the criteria of the dichotomous logistic Rasch model. In essence, the aim was to construct a scale consisting of approximately five positively and five negatively formulated items, and that would be used in survey research, be easy to administer, and be suitable for lonely and nonlonely individuals.

\section{Testing the Rasch Model}

The Rasch model is designed for dichotomous variables, whereas the latent trait is assumed to be continuous. The four assumptions underlying the Rasch model are (1) unidimensionality, (2) local stochastic independence, (3) monotonicity, and (4) sufficiency of simple sum statistics. (For an introduction to the Rasch model, see Roskam, 1982; van den Wollenberg, 1979; Wright \& Stone, 1979.) These assumptions are difficult to satisfy, and it is not always possible to check whether they have been violated (Wood, 1978).

The majority of the goodness-of-fit tests of the Rasch model are based on the invariance of the item difficulties over samples. The invariance of item difficulties must also hold if the sample is divided on the basis of characteristics such as race, sex, or test-score profiles. In general, to test the model, the Andersen (1973) likelihood ratio test is applied on the basis of a categorization according to high or low total scores. To control for bias, an 
Table 1

List of 28 Items Including their Scale Characteristics: Percentage Agreeing, Item Total Correlation, Molenaar's U Statistic

\begin{tabular}{|c|c|c|c|}
\hline Item & $\%$ & $\mathrm{r}$ & $\mathrm{U}$ \\
\hline \multicolumn{4}{|l|}{ Severe deprivation (L1) } \\
\hline 6. I wish I had a really close friend.a & 27 & .56 & -1.61 \\
\hline 17. I experience a sense of emptiness around me.a & 20 & .60 & -2.47 \\
\hline $\begin{array}{l}\text { 28. There's no one really that I would like to } \\
\text { share my ups and downs with.a }\end{array}$ & 31 & 31 & 5.73 \\
\hline 21. I don't really have any friends. & 28 & .37 & 2.09 \\
\hline 22. There is no one who is particularly interested & & & \\
\hline in you. a & 31 & .28 & 5.73 \\
\hline 12. Often, I feel rejected.a & 20 & .62 & -2.64 \\
\hline $\begin{array}{l}\text { 23. You can no longer expect any interest from } \\
\text { even your own family. }\end{array}$ & 32 & .40 & 1.70 \\
\hline \multicolumn{4}{|l|}{$\begin{array}{l}\text { Deprivation feelings connected with specific } \\
\text { problem situations such as abandonment (L2) }\end{array}$} \\
\hline $\begin{array}{l}\text { 4. There are only a few people with whom you can } \\
\text { really talk. }\end{array}$ & 72 & .41 & -.19 \\
\hline 15. There are only a few people who take the & & & \\
\hline trouble to listen to you. & 52 & .48 & .69 \\
\hline $\begin{array}{l}\text { 14. When you feel good, you may be welcome, } \\
\text { but when you're depressed it's quite a }\end{array}$ & & & \\
\hline \multicolumn{4}{|l|}{$\begin{array}{l}\text { different matter. } \\
\text { 9. Recently, I feel misunderstood even by my }\end{array}$} \\
\hline closest familoy. & 24 & .43 & -.24 \\
\hline 24. I miss having people around me.a & 18 & .53 & -1.31 \\
\hline \multicolumn{4}{|l|}{ 3. I have lost all my friends from previous } \\
\hline years. & 40 & .45 & 2.02 \\
\hline 20. I feel I'm a prisoner in my own home. & 20 & .51 & -1.21 \\
\hline \multicolumn{4}{|l|}{ Missing companionship (L3) } \\
\hline \multicolumn{4}{|l|}{ 8. It makes me sad that I have no company } \\
\hline $\begin{array}{l}\text { 18. I feel ignored by people in my neighborhood. } \\
\text { 2. I wish I had contact with my neighbors, }\end{array}$ & 14 & .46 & -1.30 \\
\hline and that they would drop in on me. & 23 & .47 & -.18 \\
\hline $\begin{array}{l}\text { 29. I feel my circle of friends and } \\
\text { acquaintances is too limited. }\end{array}$ & 29 & .59 & -2.42 \\
\hline 11. The neighbors are very cold. & 39 & .45 & .86 \\
\hline \multicolumn{4}{|l|}{ A feeling of sociability (L4) } \\
\hline $\begin{array}{l}\text { 13. There are a few people that I have pleasant } \\
\text { contact with. }\end{array}$ & 14 & .38 & .20 \\
\hline $\begin{array}{l}\text { 5. There are several people in the neighborhood } \\
\text { that I can go to for a cosy chat. }\end{array}$ & 40 & .43 & 1.05 \\
\hline 25. There is always someone around that I can & & & \\
\hline talk to about my day to day problems. & 28 & .53 & -.41 \\
\hline \multicolumn{4}{|l|}{ A feeling of having meaningful relationships (L5) } \\
\hline $\begin{array}{l}\text { 26. There are plenty of people that I can depend } \\
\text { on if } I^{p} \mathrm{~m} \text { in trouble. }\end{array}$ & 37 & .57 & -1.86 \\
\hline 30. There are enough people that I feel close & & & \\
\hline to. & 31 & .57 & -1.47 \\
\hline $\begin{array}{l}\text { 10. I can rely on my friends whenever I need } \\
\text { them. }\end{array}$ & 31 & .54 & -1.67 \\
\hline 1. I have a number of friends that I can rely & 33 & .47 & \\
\hline 19. There are many people that I can count on & & & \\
\hline completely. & 53 & .49 & .04 \\
\hline $\begin{array}{l}\text { 7. There are enough people who accept me for } \\
\text { what I am. }\end{array}$ & 18 & .47 & -.75 \\
\hline
\end{tabular}

Note. Item 16 and item 27 have been deleted.

aThese items were included in the nine-item deprivation scale.

Two items from this scale are not privided here: "I miss a man/

woman, especially mine" and "I regret not having a mate".

Downloaded from the Digital Conservancy at the University of Minnesota, http://purl.umn.edu/93227. May be reproduced with no cost by students and faculty for academic use. Non-academic reproduction requires payment of royalties through the Copyright Clearance Center, http://www.copyright.com/ 
additional test on the basis of other relevant criteria can be performed.

Following Molenaar (1983b), exploratory rather than confirmatory techniques were used in the development of the Rasch-based loneliness scale. More specifically, the Molenaar $U$ statistic (Molenaar, 1983b) and the BINO procedure in the PML computer program (Gustafsson, 1979) were used, both of which are binomial tests per item score group that provide information on the individual items, and are particularly suited to detect violations of the assumptions of monotonicity and the sufficiency of simple sum statistics. In addition, the so-called "splitter" technique (Molenaar, 1983b; van den Wollenberg, 1979) was applied to check the assumptions of unidimensionality and local stochastic independence. ${ }^{1}$

The advantages of the Rasch model for test or scale construction should be evident from the previous description. First, the model can be considered a form of fundamental measurement, that is, model assumptions can be used to test or check the model. The second advantage reveals itself in practice. When the test or scale items fit the model, test calibration, item banking, scaling problems and such, can be solved within the Rasch framework in a rather substantial and easy manner.

\section{Nethod}

\section{Selection of Item}

Items were selected, beginning with the nine items of the deprivation scale. Additional items were obtained from open-ended interviews with lonely people. This procedure resulted in a list of 40 items. A jury of 20 staff members of the Department of Research Methods at the Free University of Amsterdam assisted in evaluating the items according to the items' positions on a continuum,

The more sophisticated tests of these assumptions as described by van den Wollenberg (1982), Molenaar (1983b) and more recently by Kelderman (1984) were not applied. First, these techniques were not yet implemented in the local Rasch model computer program, and second, they require very large sample sizes ranging from -11 , representing intimacy, belonging, and understanding, to +11 , representing unbearable forms of severe loneliness. The method of equal-appearing intervals (Edwards, 1957) was used for the evaluations. Because of the lack of consensus concerning them, 7 of the 40 items were excluded from the analysis. An additional five items that were found to be applicable to specific categories of respondents only were removed from the analysis as well. Thus, the investigation started with a set of 28 items, 9 of which were positively worded, with the remaining items phrased negatively. In contrast with the 9-item deprivation scale, the set included a number of items tapping slight or moderate feelings of loneliness, such as items applying to relationships with neighbors or acquaintances. The word loneliness was not mentioned in any of these items, which is similar to a procedure adopted by Russell (1982). The items are listed in Table 1.

Based on the jury ratings, the items were divided into the following groups, each differing according to the degree of severity of experienced loneliness: (1) subscale L1 - severe deprivation, with mean item scores between 8.50 and 7.75 ; (2) subscale L2-deprivation feelings connected with specific problem situations such as abandonment, with mean scores between 7.00 and 5.50 ; (3) subscale $\mathrm{L} 3-$ missing companionship, with mean item scores between 4.50 and 2.85 ; (4) subscale LA- a feeling of sociability, with mean item scores between -5.00 and -5.65 ; and (5) subscale L5-a feeling of having meaningful relationships, with mean item scores between -6.50 and -9.00 .

\section{Sulbjects}

The set of 28 items was used in a survey among unemployed, disabled, and employed individuals, including their partners. The Dutch government office, "Sociaal en Cultureel Planbureau," together with the staff of the Faculty of Social Sciences at the University of Utrecht, initiated a research project aimed at comparing the financial, social, and emotional well-being of unemployed and disabled individuals with the well-being of employed individuals. More than 1,600 men and women 
were interviewed in 1982 and 1983. At the end of each interview, the respondents were invited to participate in a follow-up study for which they were requested to complete a questionnaire concerning interpersonal relationships and experiences of loneliness.

\section{Question}

The questionnaire was constructed following the Total Design Method procedures (Dillman, 1978; Nederhof, 1981). The questionnaire consisted of several loneliness measuring instruments in addition to the previously mentioned 28 -item scale. Included were a self-rating loneliness scale, scales assessing the frequency and the intensity of loneliness feelings, and questions about the number, type, and intimacy of the achieved relationships. The response rate was $74 \%$. Of the 1,230 questionnaires that were returned, 1,201 proved to be acceptable for the present investigation.

\section{Restines}

\section{A Prelin耳ing}

First, the sample of 1,201 cases was randomly divided into two parts on the basis of assigned even and odd numbers. The analysis was carried out on the even-numbered cases, while the odd-numbered cases were used for the purpose of cross-validation. The positively worded items were mirrored and then dichotomized (originally the response categories were yes!, yes, more or less, no, and no!). As a cutting point for division, the category "no" was chosen because the category of indifference (more or less) is not neutral.

At this stage of the analysis, the unidimensionality of the set of 28 items was assessed. Unidimensionality is considered the most critical and basic assumption of measurement theory. This assumption can rarely be met in aptitude or attitude measurement, and its validity is difficult to test in many practical applications. Hattie (1984), for example, showed in a simulation study that nearly all the indices proposed to assess the unidimensionality of a set of items were unable to discrim- inate between cases with a single latent trait and cases with several latent traits.

A principal components analysis of the matrix of tetrachoric item intercorrelations was performed, using sPSS FACTOR (Nie, Hull, Jenkins, Steimbrenner, \& Bent, 1975), in order to estimate roughly the dimensionality of the set of 28 items. The items can be said to be roughly unidimensional if the first latent root is relatively large in comparison with the second root, and if the second root is not much larger than any of the other roots (Hambleton \& Traub, 1973; Lord, 1980). Figure $\mathbb{1}$ shows the first 10 latent roots from the set of 28 items.

Inspection of the plot reveals that the items were reasonably unifactorial. On the basis of this finding, the analysis was continued as if the set was unidimensional. The Andersen (1973) test, whereby the sample was divided on the basis of low and high total scores (high-low Andersen test), showed that the set of 28 items was not a Rasch scale: $X^{2}(27, N=557)=131.70, p<.0001$. Further analysis was required to detect the items responsible for the failure.

\section{The Irent Selection Process}

The second step in the analysis was a control for monotonicity of the item characteristic curves and for sufficiency of the total score. Binomial tests, applying Molenaar's (1983b) U statistic, were performed for each item score group. The $U$ values provide information on the relationships between the items and the latent trait, and between the items themselves. Items with a large positive $U$, that is, with a relatively flat item characteristic curve, are candidates for removal from the scale because they reveal little about the latent trait. The obtained $U$ values are provided in Table 1.

Because binomial analysis within the Rasch framework can be viewed as the counterpart of item-test correlations in classical test theory, the latter correlations have been included in Table 1 as well. The results show that the assumptions of monotonicity and sufficiency of the total score have clearly been violated. For example, the obtained $U$ value of 5.73 for item 22 is much larger than permissible within the Rasch framework. 
Figure 1

The 10 Largest Latent Roots from the

Principal Components Factor Analysis in Order of Size for the 28 Items

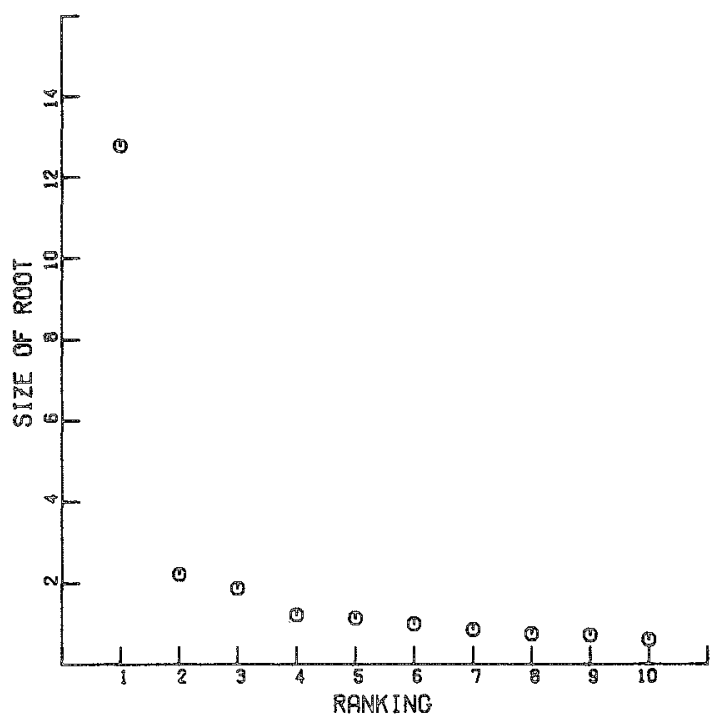

Items were selected on the basis of the following criteria: (1) the number of positively and negatively formulated items should be balanced, and (2) items from each of the five subscales should be incorporated. If several items from a particular subscale met the criteria, then the items with the highest $U$ values were excluded. This procedure resulted in six positively formulated items: item 25 from subscale $L 4$ and numbers $26,30,10,19$, and 7 from subscale L5; and six negatively formulated items: numbers 6,17 , and 12 from subscale $\mathrm{Ll}$, item 24 from subscale L2, and items 8 and 29 from subscale L3. Subscale L5 with five items is over-represented in the selected set. Thus, item 7 from subscale L5 was additionally excluded on the basis of its semantic inconsistency.

\section{Tescingng 䠹e Selected Set of litems}

In step three of the analysis, the remaining set of 11 loneliness items was tested against the Rasch assumptions. The Andersen test (high-low) on the total score indicated a good fit: $\chi^{2}(10, N=415)$
$=13.56, p=.1940$. No deviations were found for the binomial test for the individual items. There were no extremely high positive $U$ values, which were all between -1.09 and 1.87. Molenaar (1983b) claimed that the $U$ statistic has standard normal distribution when the number of persons in each score group approaches infinity. Thus, the monotonicity and the sufficiency of the total score were guaranteed.

At this stage, a more precise control for unidimensional structure and local stochastic independence was applied. The procedure involves the division of the respondent sample on the basis of an internal scale criterion, namely, the so-called "splitter" (van den Wollenberg, 1979). When an item is used as a splitter, one subgroup of respondents obtains a score of zero for that particular item, whereas the other subgroup obtains a score of one. The degree of difficulty of the remaining items can then be estimated separately for the two subgroups. Molenaar (1983b) predicted that items "measuring the same latent trait as the splitter will be more difficult for the persons scoring zero on the splitter and more easy for persons scoring one. Items unrelated to this trait should in principle be equally easy for both groups; thus the graphical plot may enable us to distinguish between the two kinds of items"' (p. 50).

In Figure 2, the splitter was item 30, "There are enough people that I feel close to." A plot of the item difficulties of one group against the item difficulties of the other shows that the items were all on or near the diagonal, indicating that the items were equally difficult for the two subgroups. An Andersen test was also performed. No deviations were found, $\chi^{2}(9, N=415)=13.81, p=.1298$, providing additional support for the unidimensionality of the set of items.

Similar plots were found for most of the items when they were used as splitters, particularly if they were moderately difficult or relatively easy. However, Figure 3 shows that a different plot was obtained when the splitter was item 17, "I experience a sense of emptiness around me." Strong interrelations between the splitter and items 8, 12, and 24 were revealed, and moderate interrelations for items 29 and $6, x^{2}(9, N=415)=101.3, p$ 
Wigare 2

Plot of the Item Difficulties (Log Scale) for the 11 Selected Items with Item 30 as the Splitter

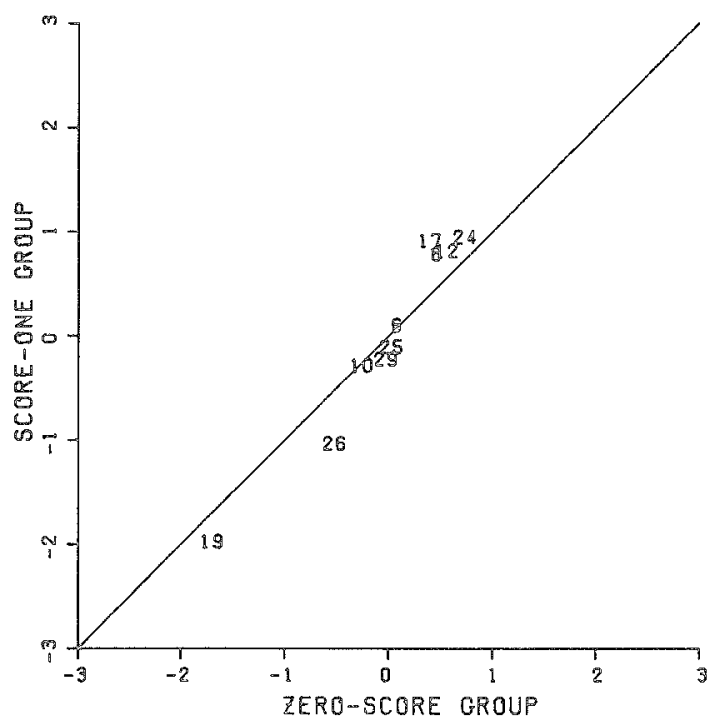

$<.0001$. These items together formed the negative scale. When item 19 functioned as the splitter (not illustrated in the figures), strong interrelations were found for items 25 and 26 , with moderate interrelations for items 10 and 30 . These particular items formed the positive scale. Thus, the splitter analysis yielded ambiguous results. Some of the plots appeared to indicate one underlying dimension or trait, whereas others indicated two underlying dimensions, traits, or separate subsets of items.

The following comments should be made. Unidimensionality was generally revealed when moderately difficult items, such as numbers 30,10 , and 6 , or when relatively easy items, such as number 26, were used as splitters. The possibility of two dimensions or subsets was indicated only when irems with relatively high or relatively low popularities, such as items 19 and 17 , functioned as splitters. The latter finding could possibly be attributed to the unreliability of difficulty estimates for such items. In this context, Molenaar (1983b) warned "that it is wise to avoid the use of spliting items with very low or very high popularities, and to inspect plots for a few different splits, placing confidence only in features that they have in common" (p. 53).

There were no theoretical grounds for bidimensionality. If a second dimension existed, it could clearly be a methodological artifact--response error (for a detailed discussion of response effects in surveys, see Sudman \& Bradburn, 1974). A study conducted by Zeller and Carmines (1980) provides support for such a notion. Using factor analysis to test the dimensionality of a set of positively and negatively phrased self-esteem items, they demonstrated that the second dimension in their research was clearly a methodological artifact. Although factor analysis cannot solve the issue of unidimensionality or bidimensionality, it can provide an indication of what is happening.

Table 2 reports the outcomes of the factor analysis, showing both an unrotated and a rotated solution. The rotated solution appeared to reveal two dimensions: a positive and a negative scalle. The unrotated solution yielded one dimension, and a possible methodological artifact-the second fac-

Figure 3

Plot of the Irem Difficulries (Log Scale) for the 11 Selected Items with Item 17 as the Splitter

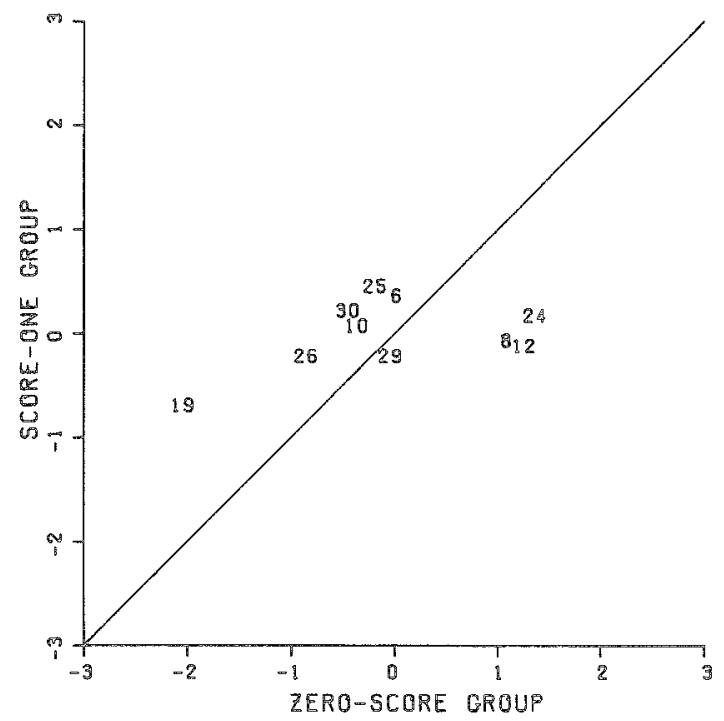


Table 2

The Scale Characteristics and the Factor Loadings of the 11 Selected Items: Item Total Correlation, Molenaar's U-statistic

\begin{tabular}{|c|c|c|c|c|c|c|c|}
\hline \multirow{3}{*}{$\begin{array}{l}\text { Item } \\
\text { number }\end{array}$} & \multirow{3}{*}{$\begin{array}{l}\text { Sub- } \\
\text { scale }\end{array}$} & \multirow[b]{3}{*}{ r } & \multirow[b]{3}{*}{ U } & \multicolumn{4}{|c|}{ Two Factor Solution } \\
\hline & & & & \multicolumn{2}{|c|}{ Unrotated } & \multicolumn{2}{|c|}{ Rotated } \\
\hline & & & & $\bar{I}$ & $\overline{\text { II }}$ & $\bar{I}$ & $\overline{\mathrm{I}} I$ \\
\hline 6 & $\mathrm{~L}_{1}$ & .57 & -.22 & .77 & -.10 & .64 & .45 \\
\hline 17 & L 1 & .59 & -1.09 & .82 & -.33 & .83 & .31 \\
\hline 12 & $\mathrm{~L} 1$ & .59 & -1.01 & .83 & -.21 & .76 & .40 \\
\hline 24 & $\mathrm{~L} 2$ & .59 & -.49 & .83 & $=.37$ & .86 & .29 \\
\hline 8 & L3 & .58 & -1.03 & .82 & -.33 & .83 & .31 \\
\hline 29 & L3 & .56 & .49 & .76 & -.12 & .65 & .42 \\
\hline 25 & $\mathrm{~L} 4$ & .53 & 1.87 & .72 & .25 & .36 & .67 \\
\hline 26 & L5 & .56 & .46 & .76 & .37 & .31 & .79 \\
\hline 30 & L5 & .59 & .14 & .79 & .27 & .40 & .73 \\
\hline 10 & L5 & .53 & 1.10 & .72 & .34 & .31 & .74 \\
\hline 19 & L 5 & .50 & 1.60 & .71 & .25 & .26 & .76 \\
\hline
\end{tabular}

tor. The finding that the positively worded items obtained second factor loadings between -.37 and -.10 , whereas the negatively worded items obtained positive second factor loadings between .25 and .37 , suggests that the second principal factor in the unrotated structure represented the positive and the negative wording of the items. A factor analysis of the total set of 28 items produced a similar structure.

\section{Cross-Validation and a

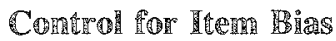

Data from the respondents who had been assigned odd numbers were used for cross-validation. Invariance of the item parameters over the odd and even respondent number subsets was demonstrated by the Andersen test, $\chi^{2}(10, N=808)=7.35, p$ $=.69$, implying that there was little danger of capitalization of chance. Finally, the invariance of the item parameters for other relevant splits of the respondent sample was checked for, again using the Andersen test (see Ironson, 1982, for more details on this procedure). The results of the Andersen tests showed that for divisions according to sex, $\chi^{2}(10, N=808)=18.19, p=.05$, and to employment status, $\chi^{2}(20, N=808)=35.79, p$
$=.02$, no or minor violations of the Rasch assumptions were found.

\section{Lonehiness Subloscales}

The next part of the analysis concentrated on the subscales of loneliness, as classified by the jury. As Table 3 shows, the seven items from subscale $\mathrm{L} 1$, "feelings of severe loneliness," mer the Rasch scale criteria, though the majority of the items appeared to be too difficult for respondents scoring low on the scale, that is, the nonlonely individuals. The 7-item subscale L2, "feelings connected with specific problem situations such as abandonment," was found to constitute a good Rasch scale as well. Finally, "missing companionship," which was the 5-item subscale L3, and five of the six items of the positive subscale L5, "feelings of having meaningful relationships," also proved to be good Rasch scales.

It can be concluded that subscales $L 1, L 2, L 3$, and $\mathbb{L} 5$ are good $R$ asch measures for feelings of severe loneliness, loneliness in problem situations, loneliness concerning missing companionship, and for the positive set, feelings of belongingness. Subscales $\mathbb{L} 2$ and $\mathbb{L} 3$ seem to be particularly suitable indicators for the less severe loneliness feel- 
Table 3

Andersen Test Results for the Loneliness Subscales

\begin{tabular}{|c|c|c|}
\hline \multirow[b]{2}{*}{ Subscale } & Andersen & Tests \\
\hline & High-Low & Men-Women \\
\hline Feelings of severe loneliness (LI), & $x^{2}=15.75$ & $x^{2}=4.19$ \\
\hline Items: $6,12,17,21,22,23,28$ & $\begin{array}{ll}\mathrm{p} & =.052 \\
(6, \quad N=723)\end{array}$ & $\begin{array}{l}\mathrm{p}= \\
(6, \quad \mathrm{~N}=7230\end{array}$ \\
\hline Loneliness of problem situations (L2), & $x^{2}=2.64$ & $x^{2}=3.84$ \\
\hline Items: $3,4,9,14,15,20,24$ & $\frac{\mathrm{p}}{(6, \quad N=941)}$ & $\begin{array}{l}\frac{p}{(6,} \quad .698 \\
(N=941)\end{array}$ \\
\hline Missing companionship (L3), & $x^{2}=9.97$ & $x^{2}=7.43$ \\
\hline Items: $2,8,11,18,29$ & $\begin{array}{l}p=\quad .048 \\
(4, N=603)\end{array}$ & $\begin{array}{l}\mathrm{p} \\
(4, \quad N=603)\end{array}$ \\
\hline Feelings of sociability (L5), & $x^{2}=3.93$ & $x^{2}=7.81$ \\
\hline Items: $1,10,19,26,30$ & $\begin{array}{l}p=.4159 \\
(4, N=654)\end{array}$ & $\frac{p}{(4, \quad N=654)}$ \\
\hline
\end{tabular}

Note. Because it consisted of such a small number of items, subscale 44 was not examined.

ings as illustrated by the mean rating scores of the items that were categorized by the jury. Subscale Ll seems to be a suitable indicator for severe loneliness.

\section{Discanssion}

The efforts to construct a scale that embraces both positively and negatively formulated items, and meets the Rasch assumptions as well, were reasonably successful. There is sufficient evidence to treat the scale in practice as a Rasch scale. These findings are inconsistent with the observations made by Molenaar (1983a) and Hox (1982) that scales which obey the Rasch criteria are difficult to construct, in particular those scales addressing a single underlying latent trait, which covers a positive as well as a negative attitude dimension.

In the item selection process, use was made of the exploratory techniques recommended by Molenaar (1983b), which provide specific information about the nature and extent of the violations of the assumptions underlying the Rasch model. Among these are the splitter technique to detect homogeneous subsers of items, and binomial tests per item to detect items with an overly flat or steep item characteristic curve (for additional informa- tion, see Sijtsma, 1983). A comparison of these techniques with classical test theory showed (1) some resemblance between Molenaar's $U$ statistic and the item-test correlation, and (2) roughly the same results when unidimensionality was tested using splitter techniques or a factor analytic approach.

Neither of the last two techniques provided definite insight into the dimensionality of the 11 -item deprivation scale. The results however, pointed in the direction of unidimensionality and a methodological artifact-response set. That similar results were obtained with techniques from the Rasch framework and a number of classical tools should, of course, not be interpreted as actual proof of unidimensionality, but rather as an indication that the data conform to a unidimensional structure. The Rasch model is superior to classical test tools because it is a form of fundamental measurement, meaning that model assumptions can be tested, and that the probability that a person will agree with a particular item is predicted by a simple latent trait model.

With respect to the validity of the scale, construct representation as part of construct validity (Embretson [Whitely], 1983) was fairly well guaranteed by the Rasch tests on the deprivation con- 
struct. So far, hopeful results also have been obtained for the assessment of the nomothetic span, which Embretson sees as the second part of construct validity.

The four loneliness deprivation subscales, which were based on a theoretically derived jury-rating procedure, also met the Rasch scale criteria reasonably well. These Rasch subscales are: (1) subscale L1, feelings of severe loneliness; (2) subscale $\mathbb{L} 2$, feelings of loneliness connected with specific problem situations such as abandonment; (3) subscale $\mathrm{L} 3$, loneliness related to missing companionship; and (4) subscale L.5, the positive set, feelings of belongingness. The additional use of the four loneliness-deprivation subscales can be recommended when the description of varieties or types of loneliness is desired.

A number of research findings require further investigation. Because the present study was based on a relatively large number of respondents and items, small deviations of the $R$ asch model resulted in significant values of the test statistic. When the data from 1,201 respondents were used, the highlow Andersen test statistic for the 11 items was .005 , whereas two subsamples of approximately 600 cases produced $p$ values of .078 and .056 for the 11 items. It would be advisable to devise a Rasch power test that corrects for larger samples and larger sets of items.

It is agreed with Gustafsson (1980) and Molenaar (1983b) that the removal of items should never become a mechanical operation. Rather, factors such as item content and the social and personal relevance of the items should be taken into account. In the present analysis, the possible effect of response set was suggested. Under the assumption that the data from certain individuals or a category of individuals are responsible for the response set, the exclusion of those data could possibly clarify the problem. In the present study, for example, the data from individuals who do not have any deprivation feelings at all, and for whom the items are relatively meaningless, could be considered. Future research within the Rasch framework should focus on the development of tools for the selective elimination of data. In the past, steps in this direction have been undertaken by Wright and Stone (1979).
Although it has been argued that the Rasch model is not fully adequate for questionnaire data (Fischer, 1974, 1978), because the trait to be measured can be confounded with response style or guessing, the present results are promising. In the near future it will likely be possible to overcome problems associated with response style by the application of a polychotomous Rasch model (Embretson [Whitely], 1980, 1983; Fischer, 1974, 1978).

\section{References}

Anderberg, M. R. (1973). Clusteranalysis for applications. New York: Academic Press.

Andersen, E. B. (1973). A goodness of fit test for the Rasch model. Psychometrika, 38, 123-140.

de Jong-Gierveld, J. (1978). The construct of loneliness: Components and measurement. Essence, 2, 221-237. de Jong-Gierveld, $\$$. (1984). Eenzaamheid (Loneliness). Deventer: Van Loghum Slaterus.

de Jong-Gierveld, J., \& Raadschelders, J. (1982). Types of loneliness. In L. A. Peplau \& D. Perlman (Eds.), Loneliness: A sourcebook of current theory, research and therapy (pp. 105-109). New York: Wiley Interscience.

Dillman, D. A. (1978). Mail and telephone surveys. New York: Wiley Interscience.

Edwards, A. L. (1957). Techniques of attitude scale consiruction. New York: Appleton.

Embretson (Whitely), S. E. (1980). Multicomponent latent trait models for ability tests. Psychometrika, 45, 479-494.

Embretson (Whitely), S.E. (1983). Construct validity: Construct representation versus nomothetic span. Psychological Bulletin, 93, 179-197.

Fischer, G. (1974). Einführung in die Theorie psychologischer Tests. Bern, Switzerland: Verlag Hans Huber.

Fischer, G. (1978). Probabilistic rest models and their applications. German Joumal of Psychology, 2, 298319.

Gordon, S. (1976). Lonely in America. New York: Simon and Schuster.

Gustafsson, J. E. (1979). PML: A computer program for conditional estimation and testing in the Rasch model for dichotomous items (Report No. 85). Göteborg: University of Göteborg.

Gustafsson, J. E. (1980). Testing and obtaining fit of data to the Rasch model. British Journal of Mathematical and Statistical Psychology, 33, 205-233.

Hambleton, R. K., \& Traub, R. E. (1973). Analysis of empirical data using two latent trait models. British Journal of Mathematical and Statistical Psychology, $26,195-211$.

Hartog, J., Audy, J. R., \& Cohen, Y. A. (Eds.) (1980). 
The anatomy of loneliness. New York: International University Press.

Hattie, J. (1984). An empirical study of various indices for determining unidimensionality. Multivariate Behavioral Research. 19, 49-78.

Hox, J. J. (1982). Positive and negative affect in subjective well-being: An application of the Rasch model (Publication No. 17). Amsterdam: Subfaculteit Opvoedkunde University of Amsterdam.

Ironson, G. $\mathbb{H}$. (1982). Use of chi-square and latent trait approaches for detecting item bias. In R. A. Berk (Ed.), Handbook of methods for detecting test bias (pp. 117-160). Baltimore: Johns Hopkins University Press.

Johnson, S. C. (1967). Hierarchical clustering schemes. Psychometrika, 32, 241-254.

Kelderman, H. (1984). Loglinear $\mathbb{R}$ asch model tests. Psychometrika, 49, 223-245.

Lord, F. M. (1980). Applications of item response theory to practical testing problems. Hillsdale NJ: Erlbaum Associates.

Molenaar, I. W. (1983a). Rasch, Mokken en schoolbeleving. In S. Lindenberg \& F. N. Stokman (Eds.), Modellen in de sociologie (pp. 195-213). Deventer: Van Loghum Slaterus.

Molenaar, I. W. (1983b). Some improved diagnostics for failure of the Rasch model. Psychometrika, 48 , $49-72$.

Nederhof, A. J. (1981). Beter onderzoek. Leiden: D.S.W.O.

Nie, N. H., Hull, C. H., Jenkins, J. G., Steinbrenner, K., \& Bent, D. H. (1975). SPSS: Statistical package for the social sciences (2nd Ed.). New York: McGrawHill.

Overall, J. E., \& Klett, C. J. (1972). Applied multivariate analysis. New York: McGraw-Hill.

Peplau, L. A., \& Perlman, D. (Eds.). (1982). Loneliness: A sourcebook of current theory, research and therapy. New York: Willey Interscience.

Rasch, G. (1960). Probabilistic models for some intelligence and attainment tests. Copenhagen: Danish Institute for Educational Research.

Rasch, G. (1966). An item analysis which takes individual differences into account. British Journal of Mathematical and Statistical Psychology, 19, 49-57.

Roskam, E. E. Ch. I. (1977). A survey of the MichiganIsrael-Netherlands-Integrated Series. In I. C. Lingoes (Ed.), Geometrical representation of relational data (pp. 289-311). Ann Arbor MI: University of Michigan.
Roskam, E. E. Ch. I. (1982). Hypotheses non fingo. Nederlands Tijdschrift voor de Psychologie, 37, 331359.

Russell, D. (1982). The measurement of loneliness. In $\mathbb{L}$. A. Peplau \& D. Perlman (Eds.), Loneliness: A sourcebook of current theory, research and therapy (pp. 81-104). New York: Wiley Interscience.

Russell, D., Peplau, L. A., \& Cutrona, C. $\mathbb{E} .(1980)$. The revised UCLA Loneliness Scale. Jommal of Personality and Social Psychology, 39, 472-480.

Russell, D., Peplau, L. A., \& Ferguson, M. (1978). Developing a measure of loneliness. Joumal of Personality Assessment, 42, 290-294.

Sijtsma, K. (1983). Rasch-Homogeniteit Empirisch Ornderzocht. Tijdschrift voor Onderwijsresearch, 3, 104121 .

Sudman, S., \& Bradburn, N. M. (1974). Response effects in surveys: A review and synthesis. Chicago: Aldine.

van den Wollenberg, A. L. (1979). The Rasch model and time-limit tests. Nigmegen: Stichting Studentenpers.

van den Wollenberg, A. L. (1982). Two new test siatistics for the Rasch model. Psychometrika, 47, 123140.

Weiss, R. S. (1974). Loneliness: The experience of emotional and social isolation. Cambridge MA: MPT Press.

Wood, R. (1978). Fitting the Rasch model: A heady tale. British Journal of Mathematical and Statistical Psychology, 31, 27-32.

Wright, B. D., \& Stone, M. H. (1979). Best test design: Rasch measurement. Chicago: MESA Press.

Zeller, R. A., \& Carmines E. G. (1980). Measurement in the social sciences: The link between theory and data. New York: Cambridge University Press.

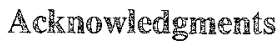

The authors are indebted to Ivo Molenaar, Joop Hox, and Pearl Dykstra for their sympathetic, but thorough, criticisms of earlier versions. Helpful suggestions from two anonymous reviewers are gratefully acknowledged.

\section{Antheror's Adderess}

Send requests for reprints or further information to Jenny de Jong-Gierveld, Vakgroep Methoden en Technieken, Free University, Valeriusplein 14, $1075 \mathrm{BH}$ Amsterdam, The Netherlands. 